\title{
Fatal ventricular tachycardia in association with propafenone, a new class IC antiarrhythmic agent
}

\author{
A. W. NATHAN \\ M.B., M.R.C.P. \\ R. S. BEXTON \\ D.M., M.R.C.P. \\ K. J. HELLESTRAND \\ A. J. CAMM \\ Ph.D., F.R.A.C.P. \\ M.D., M.R.C.P. \\ Department of Cardiology, St Bartholomew's Hospital, London ECIA $7 B E$
}

\begin{abstract}
Summary
A man with a past history of malignant ventricular arrhythmias occurring late after myocardial infarction was admitted for assessment. Monitoring revealed frequent ventricular premature beats and occasional non-sustained runs of ventricular tachycardia. Other drugs having failed, he was started on oral propafenone which is a new Vaughan Williams class IC antiarrhythmic agent. Several hours after starting this drug he had incessant ventricular tachycardia and subsequently died. Other class IC agents have been shown to have a high incidence of proarrhythmic effects, and particular care should be taken with these potent new drugs.
\end{abstract}

KEY WORDS: propafenone, proarrhythmic effects, ventricular tachycardia, ischaemic heart disease, metabolic acidosis.

\section{Introduction}

Propafenone (Podrid and Lown, 1982) is one of a new subgroup (IC) of Vaughan Williams class I antiarrhythmic agents (Harrison et al., 1981) which is extensively used in continental Europe and which may be introduced into Britain and the United States in the near future. Other members of this group include encainide and flecainide, and both of these have recently been reported to have a significant incidence of proarrhythmic effects (Winkle et al., 1981; Muhiddin et al., 1982; Nathan et al., 1984). We report a case in which propafenone caused a fatal exacerbation of ventricular tachycardia.

\section{Case report}

A 63-year-old man had recurrent ventricular tachycardia in association with ischaemic heart disease. He had sustained an anterior myocardial infarction at the age of 48 years followed by an inferior infarct 13 years later. This was complicated by ventricular tachycardia and he was subsequently treated with oral mexiletine. Six months later, he had recurrent ventricular tachycardia and was successfully resuscitated from ventricular fibrillation on one occasion. Coronary angiography demonstrated complete occlusion of both the left anterior descending and right coronary arteries with poor distal vessels, and left ventriculography showed a large cavity with extensive apical and inferior akinesis and an overall ejection fraction of $20 \%$. It was decided to continue medical therapy. Disopyramide, amiodarone, flecainide, aprindine and bethanidine were all tried over the next 11 months, but none of these agents achieved adequate control of the arrhythmia. The patient was readmitted and all antiarrhythmic drugs were stopped for 3 weeks. Electrocardiographic surveillance revealed frequent ventricular premature beats, as well as occasional non-sustained runs of ventricular tachycardia which were associated with dizziness. Oral propafenone at a dose of $150 \mathrm{mg} \mathrm{8-}$ hourly was commenced and initially there was a decrease in the number of ventricular premature beats. Four hours after the second dose, frequent, and progressively more sustained, runs of irregular tachycardia were noted, and these were demonstrated to be of ventricular origin by simple electrophysiological study. After a further $3 \mathrm{hr}$, the tachycardia was virtually incessant (Fig. 1). At this time, the plasma propafenone level was $586 \mathrm{ng} / \mathrm{ml}$ (therapeutic range approximately $500-1500 \mathrm{ng} / \mathrm{ml}$ ), and the plasma potassium concentration $4.3 \mathrm{mmol} /$ litre. Despite relatively stable haemodynamics (systolic blood pressure $100 \mathrm{mmHg}$ and no clinical or radiological signs of acute heart failure), the patient started hyperventilating. Arterial blood gases were compatible with a compensated metabolic acidosis $\left(\left[\mathrm{H}^{+}\right] 41 \cdot 5 \mathrm{nmol} /\right.$ litre $\mathrm{PO}_{2} 14.6 \mathrm{kPa}, \mathrm{PCO}_{2} 1.5 \mathrm{kPa}$, base excess -15.3 $\mathrm{mmol} / \mathrm{litre})$. During the brief periods of sinus 


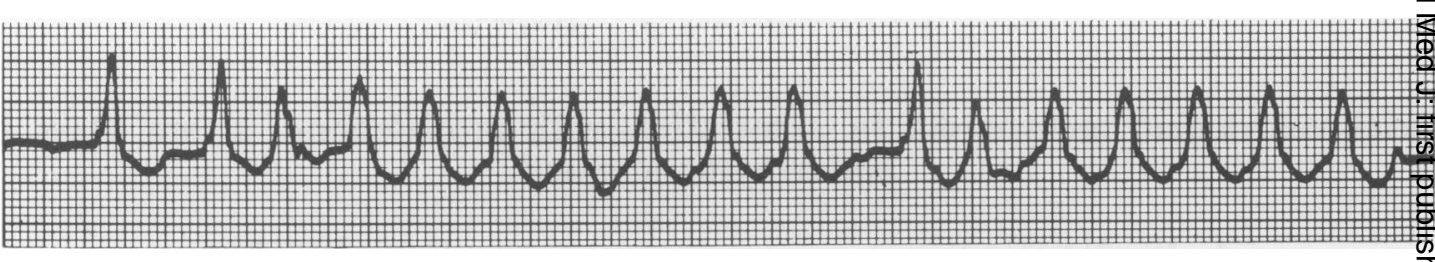

FIG. 1. Irregular ventricular tachycardia following the administration of propafenone.

rhythm, the QRS width was $140 \mathrm{~ms}$, with a QT of 380 $\mathrm{ms}$ and JT of $240 \mathrm{~ms}$ compared to a pre-treatment QRS of $120 \mathrm{~ms}$, QT of $360 \mathrm{~ms}$ and an unchanged JT of $240 \mathrm{~ms}$. There were no new signs of ischaemia. The arrhythmia gradually slowed with associated haemodynamic impairment, and despite resuscitative measures, including various pacing modalities, the patient died.

\section{Discussion}

This patient had stable ventricular arrhythmias in the 3 weeks before receiving propafenone. Amiodarone, a very long acting drug, was stopped 10 months before this, and no other antiarrhythmic drugs were given in the 3 weeks before the fatal arrhythmia. It is likely that the exacerbation of ventricular tachycardia in this man was caused by propafenone. Acidosis has not previously been reported with propafenone and its significance in this case is uncertain.

Class IC antiarrhythmic drugs slow phase zero of the action potential, but have little or no effect on repolarization (Harrison et al., 1981). They are potent antiarrhythmic agents and act principally by depressing conduction in all varieties of myocardial tissue. Almost all effective antiarrhythmic drugs have been implicated in causing proarrhythmic effects. Arrhythmias caused by class IA drugs such as quinidine and disopyramide are thought to be due to temporal dispersion of refractory periods and non-uniform recovery of fibres, causing an overall prolongation of repolarization with increases of the QT and JT intervals. In contrast, class IC drugs, which seem to be particularly prone to causing proarrhythmic effects in patients with impaired myocardial function (Nathan et al., 1984), cause little or no change in repolarization but produce their adverse effects by slowing conduction, thus creating an unfavourabje imbalance between conduction and refractoriness. Any change in the QT interval is due to lengthenifg of the QRS duration, and the JT interval usually: unchanged.

Class IC antiarrhythmic agents are potent at important additions to the drugs already availabe, but caution must be exercised in their use, partignlarly in patients with severely impaired myocardgal function.

\section{Acknowledgments}

A. W. Nathan, R. S. Bexton and A. J. C. Camm are all supgorted by the British Heart Foundation.

\section{References}

Harrison, D.C., Winkle, R.A., Sami, M. \& Mason, J.W. (19\%) Encainide: a new and potent antiarrhythmic agent. In: Carळac arrhythmias. $A$ decade of progress (Ed by D. C. Harrison), p. सी6. G. K. Hall Medical Publishers, Boston.

Muhiddin, K., Nathan, A.W., Hellestrand, K.J., Banim, S.O.8 CAMM, A.J. (1982) Ventricular tachycardia associated whth flecainide. Lancet, ii, 1220

Nathan, A.W., Hellestrand, K.J., Bexton, R.S., Banim, S. $\vec{\theta}$., SPURRELL, R.A.J. \& CAMM, A.J. (1984) The proarrhythmic effectsts of the new 'antiarrhythmic' agent flecainide acetate. American Heart Journal, (in press).

PODRID, P.J. \& Lown, B. (1982) Propafenone-an effective antiarrhythmic agent for ventricular tachycardia. Circulation, 66 (Sujpl. II), 68.

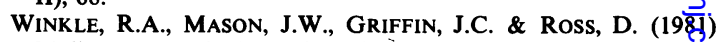
Malignant ventricular tachyarrhythmias associated with the usef encainide. American Heart Journal, 102, 857.

(Accepted 10 March 1983) 